\title{
Effect of carbon on cryogenic tensile behavior of CoCrFeMnNi-type high entropy alloys
}

\author{
M.V. Klimova, A.O. Semenyuk, D.G. Shaysultanov, G.A. Salishchev, S.V. Zherebtsov, \\ N.D. Stepanov*
}

Laboratory of Bulk Nanostructured Materials, Belgorod State University, Pobeda 85, Belgorod, 308015, Russia

\section{A R T I C L E I N F O}

\section{Article history:}

Received 11 July 2019

Received in revised form

23 August 2019

Accepted 24 August 2019

Available online 26 August 2019

\section{Keywords:}

High entropy alloys

Interstitial alloys

Microstructure

Mechanical properties

Transmission electron microscopy

\begin{abstract}
A B S T R A C T
High entropy alloys (HEAs) with a face-centered cubic (fcc) structure are considered as promising structural materials, in particular due to their impressive ductility and toughness at cryogenic temperature; at the same time strength of these HEAs is often quite low. An addition of interstitial elements like carbon substantially increases the strength of the fcc HEAs at room temperature, however the effect of $C$ on cryogenic properties has not been properly studied. Therefore in this work we examined cryogenic tensile behavior of the fcc high entropy alloys with different carbon content ( $0-2$ at.\%). The alloys had non-equiatomic proportions of principal elements, i.e. $\mathrm{Co}_{1} \mathrm{Cr}_{0.25} \mathrm{Fe}_{1} \mathrm{Mn}_{1} \mathrm{Ni}_{1}$. The lower $\mathrm{Cr}$ concentration in comparison with the equiatomic alloy led to the higher solubility of carbon confirmed by both ThermoCalc calculations and experimental results; only in the alloy with 2 at.\% $\mathrm{C}$ a small $(<1 \%)$ fraction of $\mathrm{Cr}$ rich $\mathrm{M}_{7} \mathrm{C}_{3}$ carbides was found in the as-cast condition. The microstructure of the alloys was not significantly affected by the carbon content and generally consisted of coarse $(250-300 \mu \mathrm{m})$ fcc phase grains with dendritic segregations. In turn, the carbon content influenced on mechanical behavior substantially: the strength of the alloys progressively increased with the carbon content along with some reduction in ductility. Solid solution strengthening by carbon at $77 \mathrm{~K}$ was much stronger than that at room temperature: $67 \mathrm{MPa} /$ at\% and $178 \mathrm{MPa} /$ at\%, respectively. The increase in solid solution strengthening agreed well with an anticipated increase in lattice friction at lower temperatures. Plastic deformation was associated with dislocations slip both at $293 \mathrm{~K}$ and $77 \mathrm{~K}$; a decrease in temperature and an increase in the carbon concentration increased the inclination to planar slip. The obtained results offer new approaches to increase the cryogenic properties of fcc HEAs.
\end{abstract}

() 2019 Elsevier B.V. All rights reserved.

\section{Introduction}

The so-called high entropy alloys (HEAs) have been attracting significant attention from materials scientists worldwide over the last two decades [1,2]. Initial works strongly emphasized maximizing configurational entropy via the usage of multiple $(\geq 5)$ principal components taken in close to equiatomic concentrations (5-35 at.\%) [1]. High configurational entropy was supposed to stabilize disordered solid solution phase in favor of ordered or intermetallic ones. However, later it was found that high configurational entropy is neither a necessary nor sufficient condition for solid solutions formation; therefore alloys composed of multiple

\footnotetext{
* Corresponding author.

E-mail addresses: stepanov@bsu.edu.ru, stepanov.nikita@icloud.com (N.D. Stepanov).
}

principle elements can have a complex multiphase structure [2-5]. Nevertheless these alloys were revealed to have structures and properties not readily available in a conventional alloy based on single principle elements [2,6-10]. The current alloy design strategy focuses more on alloys which can fill the "gaps" in the performance of single-principle-element alloys; as such, no strict requirements on the chemical composition of these complex, concentrated alloys (CCAs) is claimed [2].

Meanwhile some of the HEAs possess a surprisingly stable solid solution single-phase structure. One of the examples is the equiatomic CoCrFeMnNi alloy, widely known as the Cantor alloy [11]. It has a face-centered cubic (fcc) single-phase structure stable at $\mathrm{T} \leq 900^{\circ} \mathrm{C}$ [12-15] and possesses quite intriguing mechanical properties, namely a combination of high strength and ductility along with exceptional fracture toughness at cryogenic temperatures [16-19]. Promising characteristics of the alloy were attributed 
to the synergy of different deformation mechanisms, in particular, dislocation slip and mechanical twinning [16,19-21]. However, quite low room temperature strength of the alloys caused a number of studies focused on an increase in the strength [15,20,22-29]. At the same time not much attention has been given to the further improvement of the cryogenic properties of the alloy [30-33].

Alloying with interstitial elements like carbon was found to be one of the most effective ways for improving the strength of $\mathrm{CoCrFeMnNi}$ and similar alloys at room temperature [34-48]. An increase in strength was associated with (i) solid solution strengthening [34,38,41,43] and/or (ii) precipitation strengthening due to carbide particles [39,42,45,47,49,50]. Although solid solution strengthening by carbon was found to be particularly effective, the equilibrium solubility of carbon in the fcc matrix of the equiatomic CoCrFeMnNi alloy was found to be rather low $\left(\sim 0.1\right.$ at.\% at $1000{ }^{\circ} \mathrm{C}$ [42]) due to the strong interaction of carbon with chromium. Carbon when dissolved in the fcc matrix can also strongly affect deformation mechanisms of the alloys by varying the stacking fault energy (SFE) [36,44,51] and/or friction stress [52]. Meanwhile controversial information on the effect of carbon on active deformation mechanisms in CoCrFeMnNi-type alloys is available $[36,37,43,46]$. Also, to the best of the authors' knowledge, very limited information on the effect of carbon on cryogenic mechanical properties of such alloys can be found in the literature $[46,53]$.

Therefore, in the present paper, we report the effect of carbon content (0-2 at.\%) on room and cryogenic tensile properties of a $\mathrm{CoCrFeMnNi-type} \mathrm{HEA.} \mathrm{To} \mathrm{increase} \mathrm{the} \mathrm{solubility} \mathrm{of} \mathrm{carbon} \mathrm{in} \mathrm{solid}$ solution, the molar fraction of $\mathrm{Cr}$ in the "base" alloy was reduced to 0.25 whereas the molar fractions of all other elements were $\sim 1$. Post-deformation microstructures were examined to estimate the effect of carbon on deformation mechanisms.

\section{Materials and methods}

Alloys used in the current study had non-equiatomic concentrations of the principal elements: $\mathrm{Co}_{1} \mathrm{Cr}_{0.25} \mathrm{Fe}_{1} \mathrm{Mn}_{1} \mathrm{Ni}_{1}$ (the subscripts indicate the molar fraction of the respective components; hereafter the $\mathrm{CoCr}_{0.25} \mathrm{FeNiMn}$ designation will be used instead of $\mathrm{Co}_{1} \mathrm{Cr}_{0.25} \mathrm{Fe}_{1} \mathrm{Mn}_{1} \mathrm{Ni}_{1}$ for the sake of simplicity). Different amounts of carbon (the nominal concentrations were $0,0.5,1.0$, and 2.0 at.\%) were added to the experimental alloys. The ingots were produced from mixtures of pure ( $\geq 99.9 \%$ ) constitutive elements by vacuum induction melting. An extra amount of Mn was added to the initial mixtures to compensate its loss due to evaporation in accordance with [16]. The produced ingots of $\sim 400 \mathrm{~g}$ had a rectangular shape measured $65 \times 40 \times 17 \mathrm{~mm}^{3}$. Results of chemical analysis (Table 1) indicated that the measured composition was close to the nominal one. The concentrations of the principal elements, listed in Table 1, were determined by energy dispersive spectrometry (EDS) analysis; the concentration of carbon was determined by LECO thermalcombustion analysis.

Specimens for microstructure analysis and mechanical testing were cut from the as-cast ingots using an electric discharge machine. X-ray diffraction (XRD), scanning (SEM) and transmission

Table 1

Chemical composition of the program alloys depending on the nominal carbon concentration, in at.\%.

\begin{tabular}{llllllll}
\hline \multirow{2}{*}{ Nominal carbon content, at.\% } & \multicolumn{7}{l}{ Concentration of the elements, at.\% } \\
\cline { 2 - 7 } & $\mathrm{Co}$ & $\mathrm{Cr}$ & $\mathrm{Fe}$ & $\mathrm{Mn}$ & $\mathrm{Ni}$ & $\mathrm{C}$ \\
\hline 0 & 23.29 & 6.22 & 23.90 & 23.09 & 23.46 & 0.03 \\
0.5 & 23.17 & 6.42 & 23.97 & 23.67 & 22.24 & 0.53 \\
1.0 & 23.14 & 6.31 & 23.13 & 23.14 & 23.34 & 0.95 \\
2.0 & 23.42 & 6.23 & 22.41 & 22.02 & 23.82 & 2.11 \\
\hline
\end{tabular}

(TEM) electron microscopy were used for structural analysis. The XRD analysis was performed using RIGAKU diffractometer and $\mathrm{Cu}$ $K \alpha$ radiation. The samples for SEM observations were prepared by careful mechanical polishing. SEM back-scattered electron (BSE) images were taken using an FEI Quanta 3D microscope equipped with an EDS detector. TEM investigations were performed using a JEOL JEM-2100 microscope operated at $200 \mathrm{kV}$ and equipped with an EDS detector. Samples for TEM analysis were prepared by conventional twin-jet electro-polishing of mechanically pre-thinned to $100 \mathrm{~mm}$ foils, in a mixture of $90 \% \mathrm{CH}_{3} \mathrm{COOH}$ and $10 \% \mathrm{HClO}_{4}$ at $30 \mathrm{~V}$ potential at room temperature.

Tensile testing was used to evaluate the mechanical properties of the alloys. Tensile tests at room (293 K) temperature (RT), or cryogenic $(77 \mathrm{~K})$ temperature of dog-bone flat specimens (gage measured $6 \times 3 \times 1 \mathrm{~mm}^{3}$ ) were conducted using an Instron 5882 universal testing machine at a constant crosshead velocity corresponded to a nominal strain rate of $10^{-3} \mathrm{~s}^{-1}$. For cryogenic testing, the test specimen and both grips were immersed in an open-top vessel filled with liquid nitrogen whose level was continuously monitored and adjusted to ensure adequate temperature control. The specimen held for a couple of minutes before the test onset to equilibrate the temperature. Elongation to fracture was determined by measurements of the spacing between marks designating the gauge length before and after the test. At least 3 specimens for each composition and temperature were tested. Extra specimens were tensioned to $20 \%$ strain; these specimens were used further for TEM examination of the deformed microstructure.

\section{Results and discussion}

\subsection{Microstructure}

Fig. 1a shows XRD patterns of the $\mathrm{CoCr}_{0.25} \mathrm{FeNiMn}$ alloy with the different carbon contents. Diffraction maximums from the fcc lattice dominated in the observed patterns; no other peaks were found even in the alloy with 2 at.\% of carbon (some variations in the peaks intensity were most likely associated with coarse grains in the as-cast structure). However, the lattice parameter of the fcc phase gradually increased from $0.3590 \mathrm{~nm}$ to $0.3613 \mathrm{~nm}$ due to an increase in the carbon content from 0 to 2.0 at.\% (Fig. 1b). Note that a linear relationship between the carbon content and the fcc lattice parameter was observed (dashed line in Fig. 1b). The slope of the line was $\approx 0.001 \mathrm{~nm} / \mathrm{at} \%$.

SEM-BSE images of microstructure of the $\mathrm{CoCr}_{0.25}$ FeMnNi alloys with the different carbon contents are shown in Fig. 2. Structure of the alloys in all conditions consisted of coarse grains $(\sim 150-200 \mu \mathrm{m})$ with dendritic segregations; in accordance with earlier obtained results [54] the interdendritic area (marked as \#1 in Fig. 2a) were found to be enriched with $\mathrm{Mn}$ and $\mathrm{Ni}$, while dendrites (\#2 in Fig. 2a) were enriched with $\mathrm{Co}, \mathrm{Cr}$, and Fe (the results of EDS chemical analysis are not shown). Some pores, visible as black dots, were also found in the alloys. An increase in the carbon content from 0 at.\% (Fig. 2a) to 0.5 at.\% (Fig. 2b) or 1 at.\% (Fig. 2c) did not result in any noticeable differences in the microstructure. Meanwhile in the alloy with the highest concentration of carbon (2 at.\% (Fig. 2d)) fine second phase(s) particles were detected at grain boundaries (high magnification insert in Fig. 2d). Unfortunately, the size and volume fraction of the particles were too small to identify them reliably using XRD/SEM techniques.

Further investigation of the $\mathrm{CoCr}_{0.25} \mathrm{FeNiMn-C}$ alloys by TEM (Fig. 3) showed that both the alloy without carbon (Fig. 3a) and the alloy with the low carbon content ( 0.5 or 1 at.\%; Fig. $3 \mathrm{~b}$ and c, respectively) had a single fcc phase structure; no signs of a second phase(s) were detected. Low-angle boundaries and dislocation walls in which individual dislocations can be recognized were 


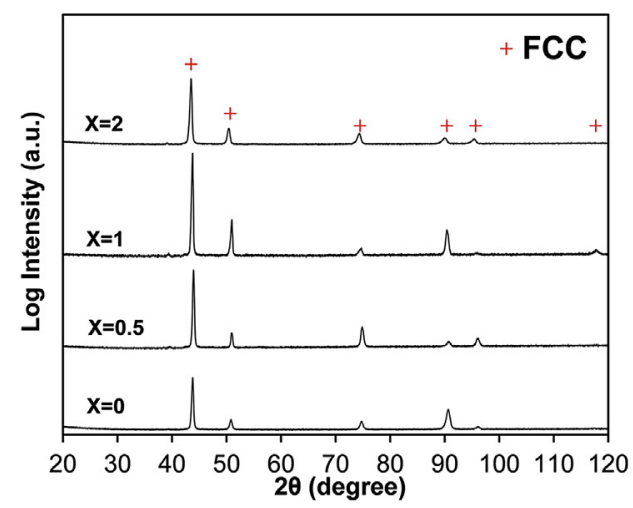

(a)

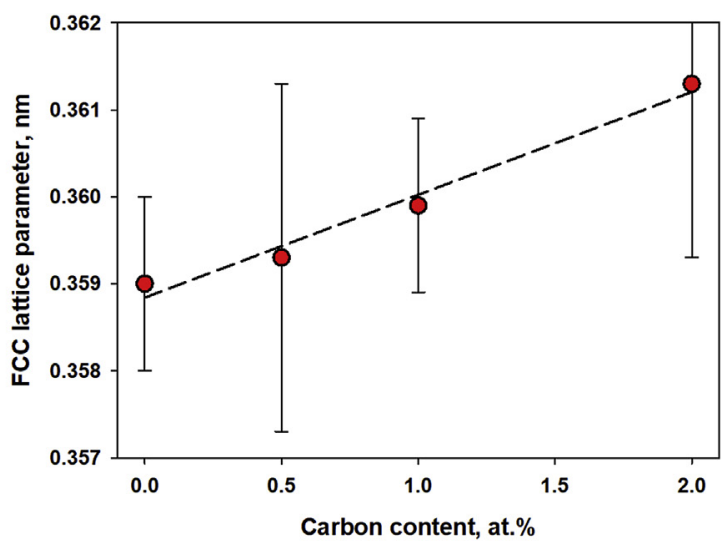

(b)

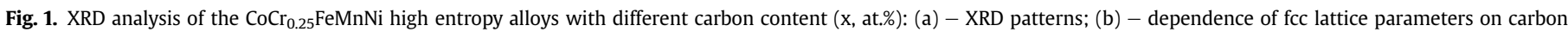
content.

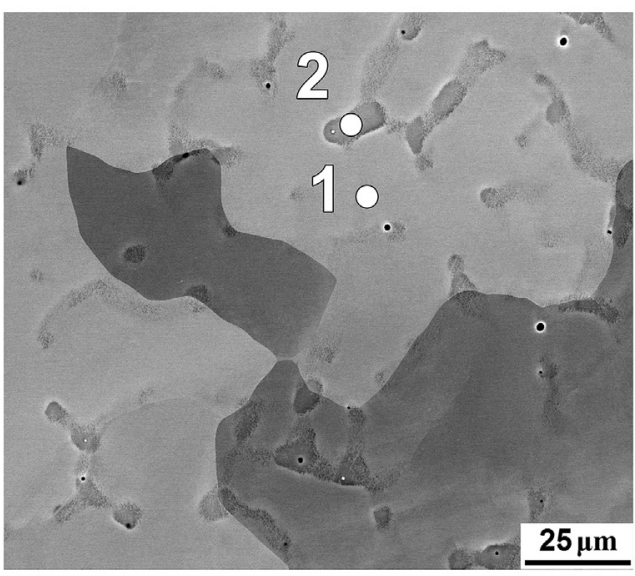

(a)

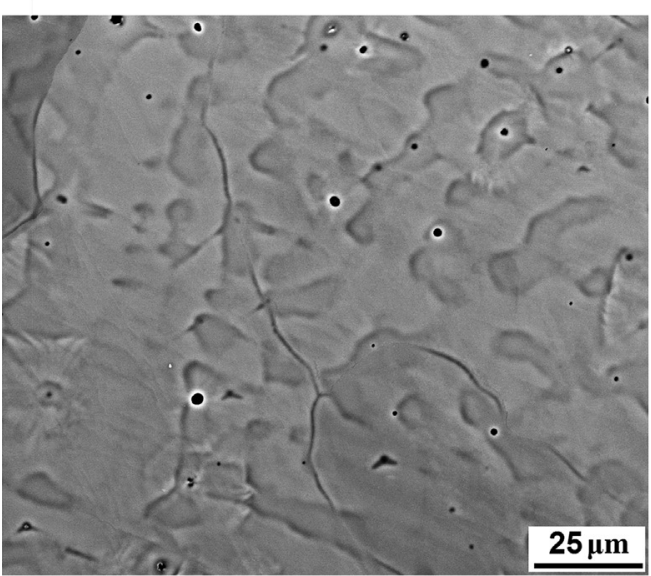

(c)

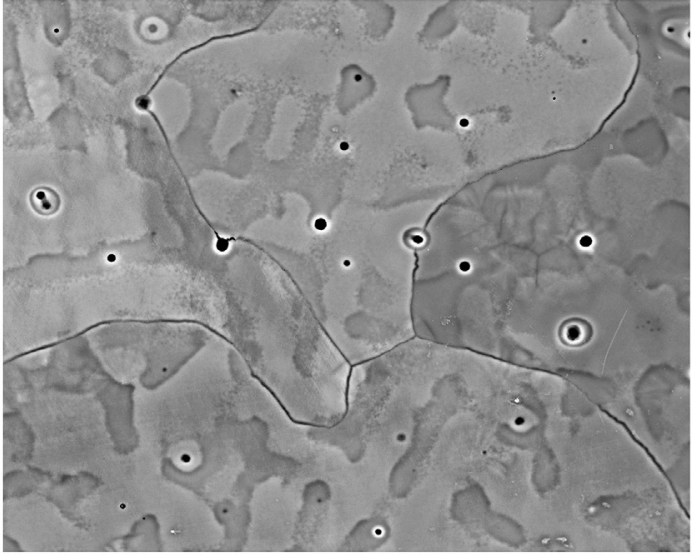

(b)

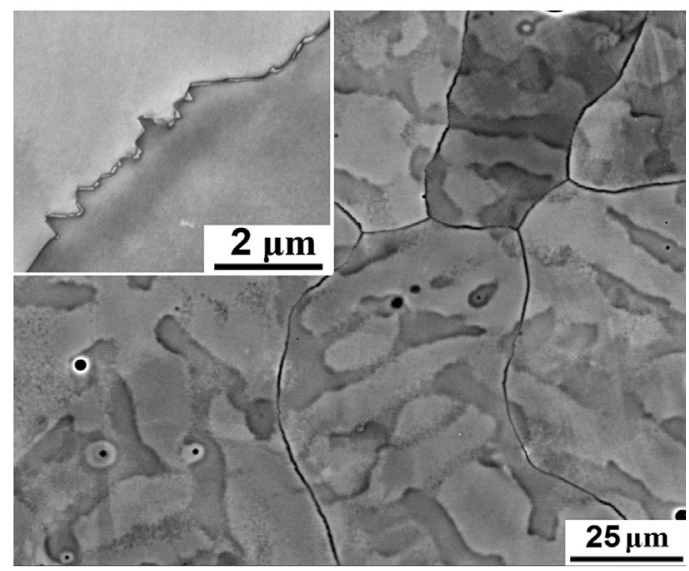

(d)

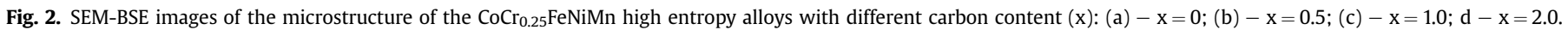

observed in the microstructure; some of the boundaries separated the dendritic and interdendritic areas. With an increase in the carbon content to 2 at.\% elongated second phase particles formed along (sub)boundaries (Fig. 3d). The length and width of the particles were $\sim 300 \mathrm{~nm}$ and $\sim 80 \mathrm{~nm}$, respectively. The particles, identified as $\mathrm{M}_{7} \mathrm{C}_{3}$ type carbides in accordance with the selected area electron diffraction patterns interpretation (insert in Fig. 3d), were composed mostly of $\mathrm{Cr}$ in accordance with EDS analysis (note 


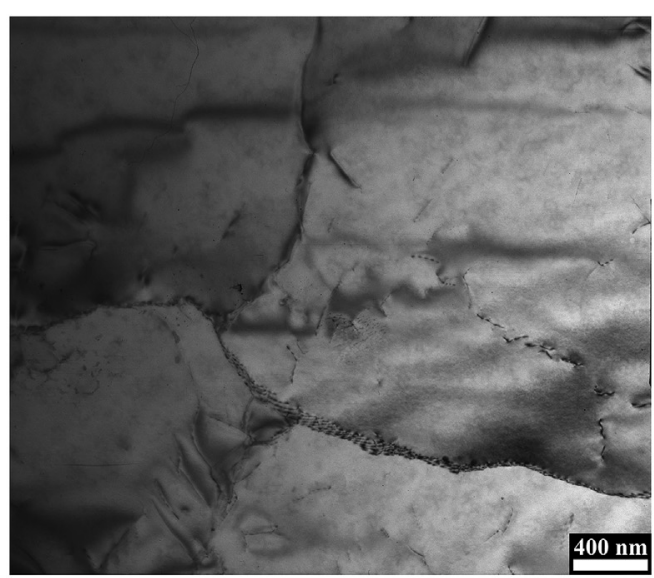

(a)

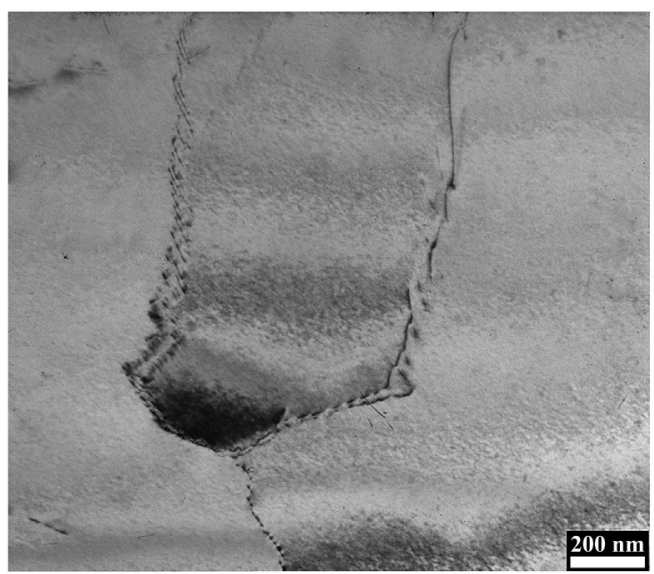

(c)

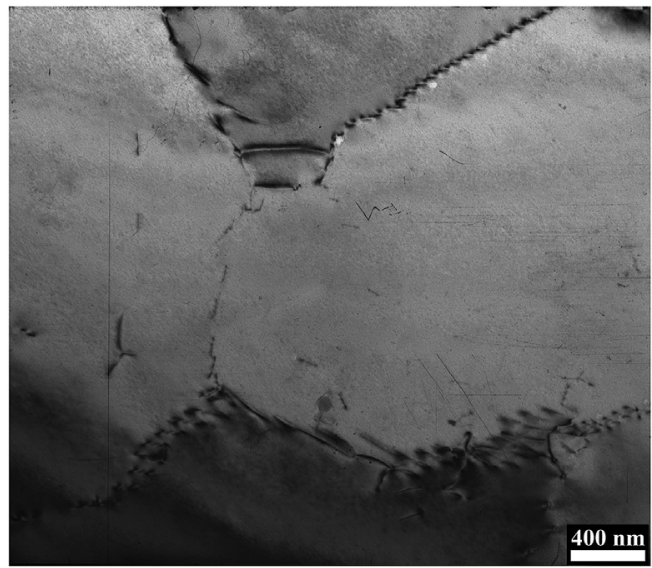

(b)

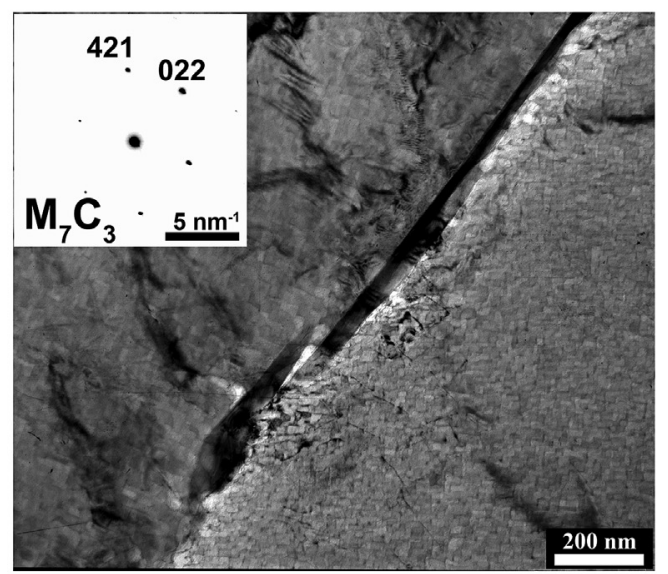

(d)

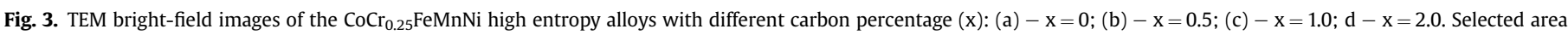
electron diffraction pattern from the second phase particle is inserted in Fig. 3d.

that the energy resolution of the EDS system used in the current study did not allow quantitative analysis of light elements like C). The volume fraction of the carbide particles was below $1 \%$.

\subsection{Tensile properties}

Fig. 4 shows tensile stress-strain curves obtained at room (Fig. 4a) or cryogenic temperatures (Fig. 4b). Resulting mechanical properties, namely yield strength (YS), ultimate tensile strength (UTS), uniform elongation (UE), and elongation to fracture (EF), are summarized in Table 2. Qualitatively, all tested alloys demonstrated rather similar mechanical behavior at both temperatures: an extensive strain hardening stage after yielding resulted in high ultimate tensile strength and considerable uniform elongation. Note that some serrations were observed at the stress-strain curves of the carbon-containing alloys at RT (insert in Fig. 4a); meanwhile no serrations were found in the same alloys at cryogenic temperature.

Quantitatively, two main trends can be drawn from the mechanical behavior analysis: (i) an increase in the carbon concentration resulted in a pronounced increase in strength of the alloys and some reduction in ductility; (ii) a decrease in the testing temperature resulted in a pronounced increase in strength and some increment in ductility (Fig. 4, Table 2). Note that ductility of the alloy with the maximum carbon percentage ( 2 at.\%) did not increase with decreasing the testing temperature. Yield strength of the alloys was especially sensitive to both the carbon content (at room temperature YS almost doubled from $185 \mathrm{MPa}$ to $320 \mathrm{MPa}$ with an increase of carbon from 0 to 2 at.\%) and deformation temperature (YS at $77 \mathrm{~K}$ was almost two times greater than that at RT $-315 \mathrm{MPa}$ and $605 \mathrm{MPa}$ at 2 at.\% C, respectively).

The dependence of the yield strength of the carbon-doped $\mathrm{CoCr}_{0.25} \mathrm{FeMnNi}$ alloys on the carbon content is plotted in Fig. 5. At both temperatures ( 293 and $77 \mathrm{~K}$ ) a linear relationship between strength and the carbon concentration is observed, however their slope significantly depended on the testing temperature: $67 \mathrm{MPa} /$ at $\%$ at $293 \mathrm{~K}$ and $147 \mathrm{MPa} / \mathrm{at} \%$ at $77 \mathrm{~K}$.

Fig. 6 shows strain hardening curves of the $\mathrm{CoCr}_{0.25} \mathrm{FeMnNi}$ alloy with different carbon contents (0, 0.5 and 2 at.\%) obtained during tensile testing at room or cryogenic temperatures. At $293 \mathrm{~K}$ the alloys showed qualitatively similar behavior irrespective of the carbon content (Fig. 6a). Strain hardening rate was 1100-1500 MPa at the initial stages of deformation with a noticeable (30-40\%) increase in the interval of strain $\varepsilon \approx 0.05-0.3$ following by a gradual decrease. The alloys with the low carbon content ( 0 or 0.5 at.\%) showed a similar maximum value of $\mathrm{d} \sigma /$ $\mathrm{d} \varepsilon \approx 1400 \mathrm{MPa}$, while the alloy with 2 at.\% of carbon reached $\mathrm{d} \sigma /$ $\mathrm{d} \varepsilon \approx 2000 \mathrm{MPa}$. 


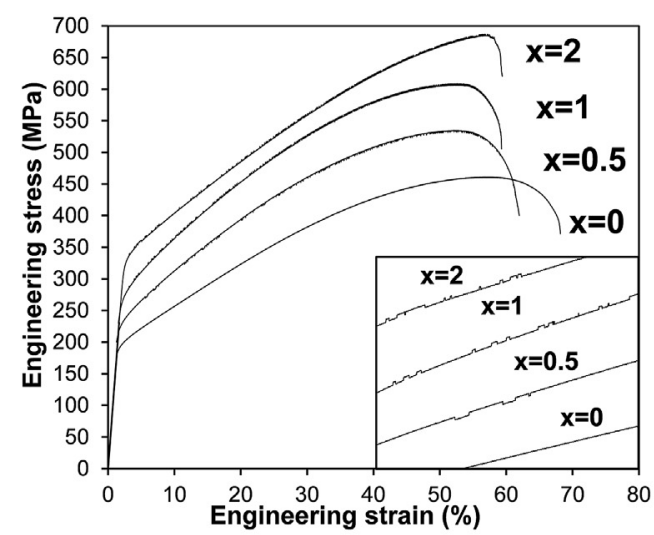

(a)

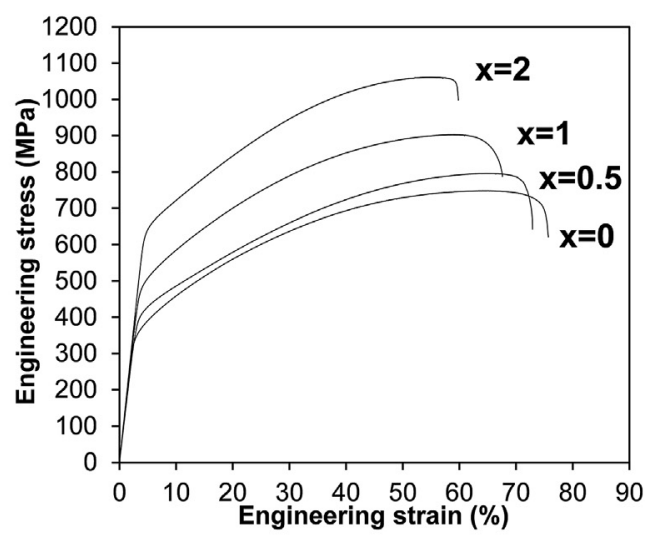

(b)

Fig. 4. Tensile stress-strain curves of the $\mathrm{CoCr}_{0.25} \mathrm{FeMnNi}$ high entropy alloys with different carbon contents obtained at different temperatures: (a) - $293 \mathrm{~K}$; (b) - $77 \mathrm{~K}$.

Table 2

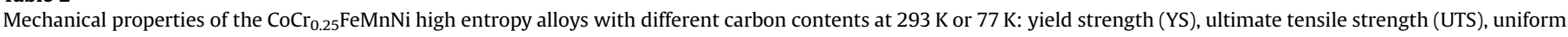
elongation (UE), and elongation to fracture (EF).

\begin{tabular}{|c|c|c|c|c|c|}
\hline Carbon concentration, at.\% & Testing temperature, $\mathrm{K}$ & YS, MPa & UTS, MPa & UE, \% & $\mathrm{EF}, \%$ \\
\hline \multirow[t]{2}{*}{0} & 77 & 315 & 750 & 59 & 70 \\
\hline & 293 & 185 & 460 & 52 & 64 \\
\hline \multirow[t]{2}{*}{0.5} & 77 & 370 & 795 & 58 & 68 \\
\hline & 293 & 215 & 535 & 47 & 58 \\
\hline \multirow[t]{2}{*}{1} & 77 & 445 & 905 & 52 & 61 \\
\hline & 293 & 255 & 610 & 48 & 55 \\
\hline \multirow[t]{2}{*}{2} & 77 & 605 & 1060 & 47 & 53 \\
\hline & 293 & 320 & 685 & 48 & 53 \\
\hline
\end{tabular}

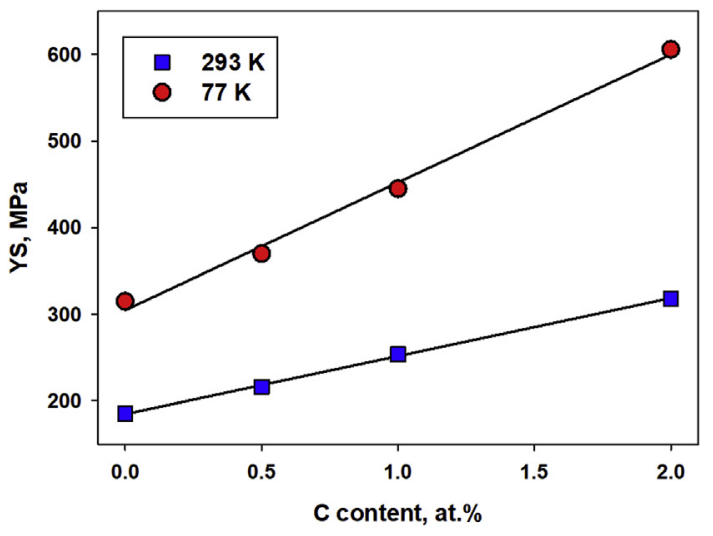

Fig. 5. Dependence of the $\mathrm{CoCr}_{0.25} \mathrm{FeMnNi}$ alloys yield strength on the carbon content at room $(293 \mathrm{~K})$ or cryogenic $(77 \mathrm{~K})$ temperatures.

At the lower temperature the values of $\mathrm{d} \sigma / \mathrm{d} \varepsilon$ at the initial stage of deformation $(\varepsilon \approx 0.05$ ) were found to be $\sim 1750-1950 \mathrm{MPa}$ for the alloys with 0 or 0.5 at.\% and $\sim 2300 \mathrm{MPa}$ for the alloy with 2 at.\% of carbon (Fig. 6b). The shapes of the curves for the alloys contained 0 or 2 at.\% of carbon were similar to those at room temperature; however the maximum values of $\mathrm{d} \sigma / \mathrm{d} \varepsilon(\sim 2000 \mathrm{MPa}$ in case of 0.5 at.\% of carbon and $2600 \mathrm{MPa}$ for the alloys with 2 at.\% of carbon) were reached at slightly lower strain $\varepsilon \approx 0.16-0.25$. Then both curves gradually decreased until a rapid drop at the final stages of deformation. The alloy with 0 at.\% of carbon showed a very slow decrease of $\mathrm{d} \sigma / \mathrm{d} \varepsilon$ to $\sim 1900 \mathrm{MPa}$ during straining at cryogenic temperature.

Serration was observed at both temperatures in all the alloys; some increase in the serration amplitude can be noticed with an increase in the carbon content at room temperature.

\subsection{Deformation microstructure}

Fig. 7 shows TEM bright-field images of the $\mathrm{CoCr}_{0.25} \mathrm{FeMnNi}$ alloy structure with $0,0.5$ or 2.0 at.\% of carbon tensioned to $20 \%$ at 293 or $77 \mathrm{~K}$. Tensile deformation of the alloy at RT resulted in the formation of elongated dislocation arrays heterogeneously distributed in the microstructure (Fig. 7a). Addition of 0.5 at.\% of carbon resulted in activation of intensive slip along a preferable direction and the formation of dislocation bands (Fig. 7c). However, boundaries of the bands were quite diffuse and sometimes masked with dislocation pile-ups located in between the bands most probably due to the operation of secondary slip systems (marked by arrows in Fig. 7c). Further increase in the carbon content to 2 at.\% resulted in more obvious planar dislocation slip with the formation of denser dislocation bands (Fig. 7e).

Deformation of the $\mathrm{CoCr}_{0.25} \mathrm{FeMnNi}$ alloy at cryogenic temperature resulted in a higher dislocation density and homogeneous dislocations distribution for all carbon concentrations (Fig. 7b, d, f), most probably due to more active operation of secondary slip systems in comparison with RT deformation. For example operating of multiple slip systems in the alloy with 0.5 at.\% of carbon during deformation at cryogenic temperature led to the formation of a cell-like structure (Fig. 7d). In the alloy with 2 at.\% of carbon multiple planar slip was also observed (Fig. 7f), however, slip was more localized in comparison with the alloy with 0.5 at.\% of carbon. In some places individual crystallographically aligned slip bands with a high dislocation density were observed (insert in Fig. 7f). 


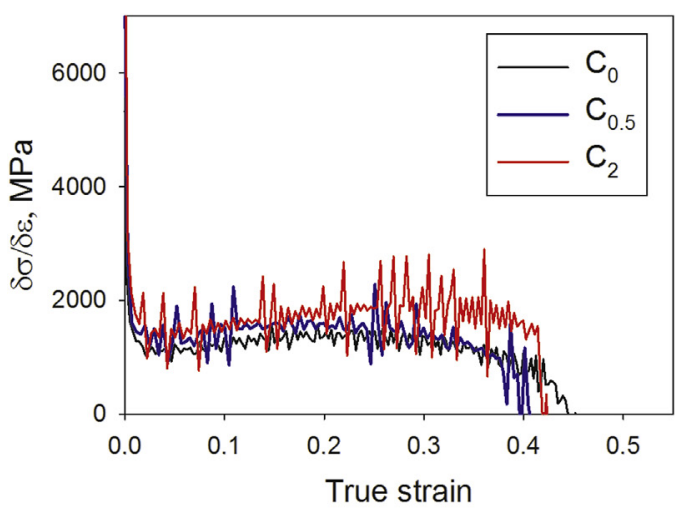

(a)

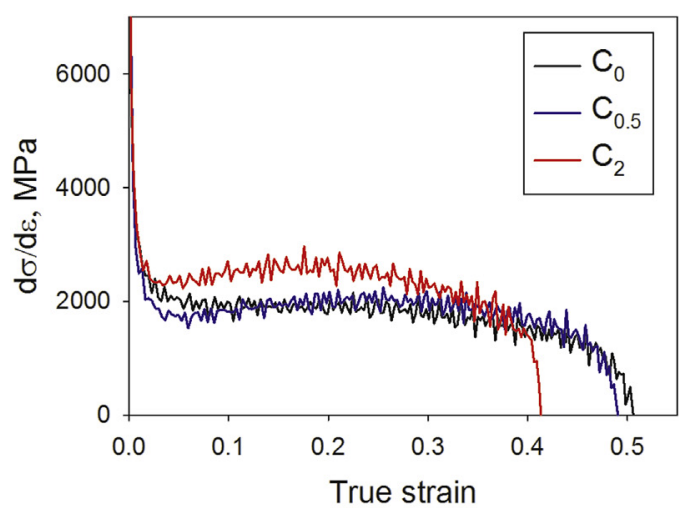

(b)

Fig. 6. Strain hardening curves of the $\mathrm{CoCr}_{0.25} \mathrm{FeMnNi}$ alloys with $0,0.5$, and 2 at.\% of carbon at: (a) - $293 \mathrm{~K}$; (b) $-77 \mathrm{~K}$.

\section{Discussion}

The present study has revealed a significant effect of carbon concentration on the mechanical properties of $\mathrm{CoCr}_{0.25} \mathrm{FeMnNi}$ alloys; this effect became even more pronounced with a decrease in deformation temperature from 293 to $77 \mathrm{~K}$. One of the important features of the program alloys was associated with a nearly single fcc phase condition, i.e. carbon was almost completely dissolved in the matrix; insignificant amount of carbides was found only in the alloy with 2 at.\% of carbon (Figs. $2 \mathrm{~d}$ and $3 \mathrm{~d}$ ). The linear dependence of the fcc lattice parameter on nominal carbon concentration (Fig. 1b) also confirmed dissolution of carbon in the alloys [42].

The single-phase structure of the program alloys is in contrast with carbon-doped equiatomic CoCrFeNiMn alloys [37,39,42] in which a lot of carbides appeared when the content of carbon was $\geq 1$ at.\%. This effect was obviously associated with different percentages of $\mathrm{Cr}$, which is the strongest carbide-forming element among all the constitutive elements of the Cantor alloy.

The effect of $\mathrm{Cr}$ on the solubility of carbon in the fcc solid solution is shown qualitatively in Fig. 8. One can clearly see that a decrease in the $\mathrm{Cr}$ molar fraction from 1 to 0.25 greatly extended the single fcc phase field toward higher carbon concentrations. For example, the equiatomic CoCrFeMnNi alloy can dissolve only 0.36 at.\% of $\mathrm{C}$ in the fcc solid solution at $1000^{\circ} \mathrm{C}$, whereas the corresponding amount for the $\mathrm{CoCr}_{0.25} \mathrm{FeMnNi}$ alloy is 1.61 at.\%. Given a strong solid solution strengthening effect of carbon (see below), a reduction in the $\mathrm{Cr}$ content with an addition of carbon can be considered as a promising alloying strategy. It should be noted however that due to non-equilibrium processes during solidification some amount of carbides can be formed in the alloy with 2 at.\% of carbon (Fig. 3d) although complete dissolution of this amount in the fcc matrix at $\mathrm{T} \geq 1040^{\circ} \mathrm{C}$ was predicted (Fig. 8).

Since except for the insignificant fraction of carbides in the alloy with 2 at.\% of $\mathrm{C}$, the microstructures of the examined alloys were almost identical, it is reasonable to suggest that the mechanical properties were mostly affected by the carbon concentration in the fcc phase, i.e. by carbon-induced solid solution strengthening. Indeed, the linear relationship between the yield strength of the alloys and the (nominal) carbon concentration is observed (Fig. 5) with the slope of $67 \mathrm{MPa} / \mathrm{at} \%$ at $293 \mathrm{~K}$. This value correlates reasonably well with the carbon-induced solid solution strengthening in stainless (76.6 MPa/at\% [55]) and TWIP steels (46 MPa/at\% [56]) and in a carbon-doped equiatomic CoCrFeMnNi alloy (65 MPa/at\% [37]). It should be noted, however, that a much higher carbon-induced solid solution strengthening effect was reported for some other fcc HEAs, for example $178 \mathrm{MPa} / \mathrm{at} \%$ for a
$\mathrm{Fe}_{40.4} \mathrm{Ni}_{11.3} \mathrm{Mn}_{34.8} \mathrm{Al}_{7.5} \mathrm{Cr}_{6}$ alloy [34]. This discrepancy can most likely be ascribed to a significant difference in the chemical compositions of these two alloys (i.e. $\mathrm{Fe}_{40.4} \mathrm{Ni}_{11.3} \mathrm{Mn}_{34.8} \mathrm{Al}_{7.5} \mathrm{Cr}_{6}$ and $\mathrm{CoCr}_{0.25} \mathrm{FeMnNi}$ ).

The solid solution strengthening effect of carbon became at cryogenic temperature $\sim 2.2$ times stronger (147 MPa/at\%) in comparison with that at RT. Solid solution strengthening is generally ascribed to the lattice friction which becomes stronger with a decrease in temperature. According to Ref. [57], the temperature ( $T$ ) dependence of the friction stress $\left(\sigma_{f r}\right)$ can be expressed as:

$\sigma_{f r}=\sigma_{f r}(0)^{*} \exp \frac{-2 \pi \omega_{0}}{\left(3 b t_{m} T\right)}$

where $\sigma_{f r}(0)$ is the friction stress at $T=0 \mathrm{~K}, \omega_{0}$ denotes the dislocation width at $T=0 \mathrm{~K}, b$ is the Burgers vector, and $T_{m}$ is the melting temperature. Using equation (1), we have calculated the ratio between $\sigma_{f r}$ at $77 \mathrm{~K}$ and $\sigma_{f r}$ at RT. $\omega_{0}=b$ was used for the calculations in accordance with the results of [57] for a number of equiatomic fcc solid solutions of the CoCrFeMnNi system. $T_{m}$ of the $\mathrm{CoCr}_{0.25-}$ FeMnNi alloy with 1 at.\% of carbon was estimated by the ThermoCalc software as $1493 \mathrm{~K}$. The results of calculations showed that the expected $\sigma_{f r}(77 \mathrm{~K}) / \sigma_{f r}(\mathrm{RT})$ ratio is 1.94 , which agrees well with the observed difference in solid solution strengthening by carbon at RT and $77 \mathrm{~K}$.

High frictional stress can be one of the reasons for intensive strengthening of the alloys during deformation (Fig. 4). In general such type of the mechanical behavior is usually ascribed to the operation of at least one of the deformation mechanisms: transformation-induced plasticity (TRIP), twinning-induced plasticity (TWIP) or microband-induced plasticity (MBIP). Each of these mechanisms gives rise to relatively high strain hardening rate which even can increase during deformation $[58,59]$ and intensive strengthening thereby attaining high elongation to fracture of the alloy. The present study did not reveal any signs of deformation twinning (or deformation-induced phase transformation) even at cryogenic temperature in contrast to the equiatomic CoCrFeMnNi alloy where intensive twinning was observed at a cryogenic temperature $[16,22,60]$. For activation of both these mechanisms (TRIP or TWIP) low stacking fault energy (SFE) is a necessary condition. Meanwhile reduction in the $\mathrm{Cr}$ content (which is particularly effective for decreasing SFE in Co-Cr-Fe-Mn-Ni alloys [61,62]) in the investigated $\mathrm{CoCr}_{0.25} \mathrm{FeMnNi}$ alloy in comparison with the equiatomic CoCrFeMnNi most probably resulted in an increase in SFE and therefore in suppression of both TRIP and TWIP mechanisms.

Strain hardening due to the formation crystallographic slip 


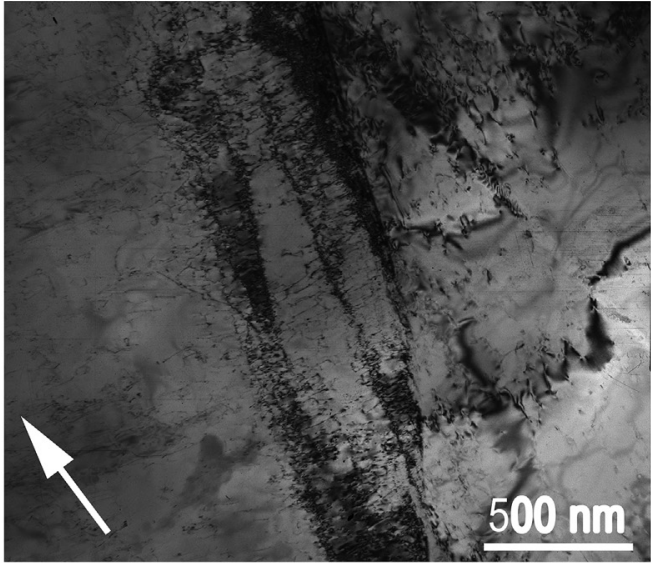

(a)

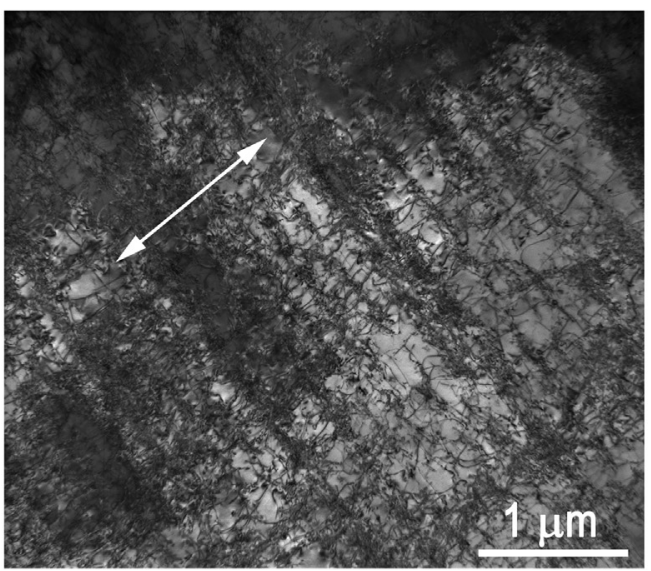

(c)

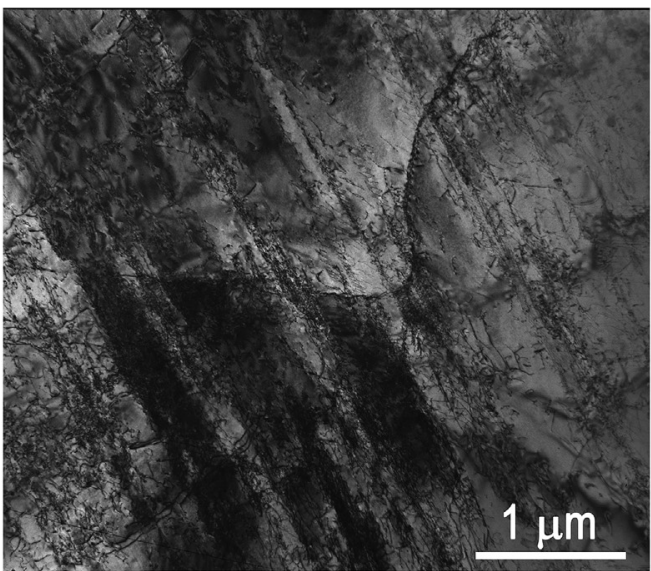

(e)

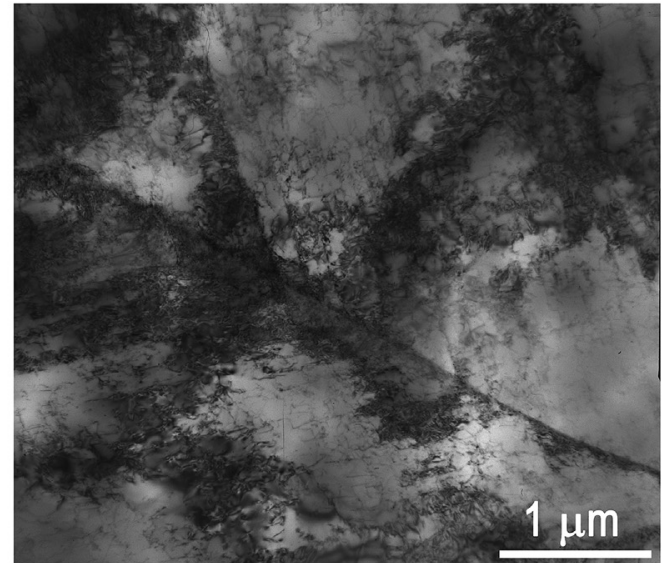

(b)

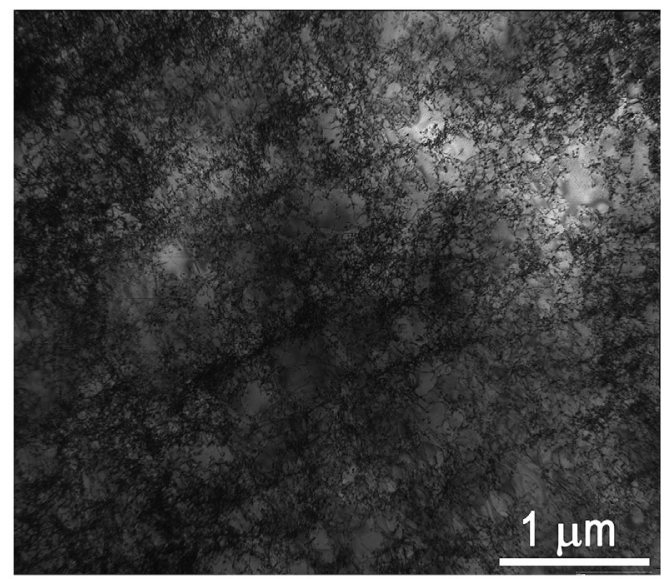

(d)

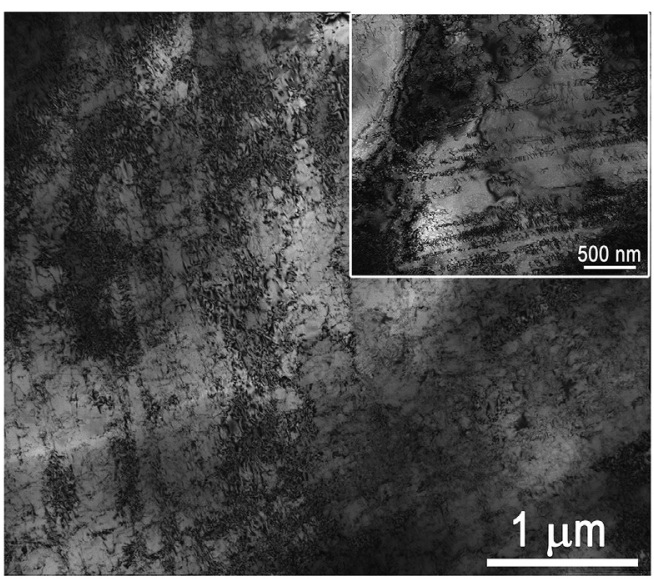

(f)

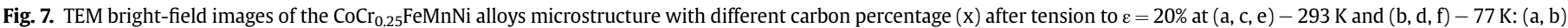
$-\mathrm{x}=0$; (c, d) $-\mathrm{x}=0.5 ;(\mathrm{e}, \mathrm{f})-\mathrm{x}=2.0$. The applied load direction is indicated with the arrow in Fig. 7a.

bands is usually associated with low SFE (which is not low enough to induce the TWIP effect, however), short-range ordering (SRO) or high friction stress $[63,64]$. The possibility of SRO is quite discussible since there are no direct experimental proofs in our case. The observed serrations at the stress-strain curves of the carbon-doped alloys (Fig. 4a) can be the indication of the SRO [65,66]. Note however that for carbon-doped $\mathrm{Fe}_{40.4} \mathrm{Ni}_{11.3} \mathrm{Mn}_{34.8} \mathrm{Al}_{7.5} \mathrm{Cr}_{6} \mathrm{HEAs}$ (up to 1.1 at. \%) atom probe tomography results showed randomly distributed atoms without formation any clusters [41]. The experience from the TWIP steels [66] suggests that there can be a few 


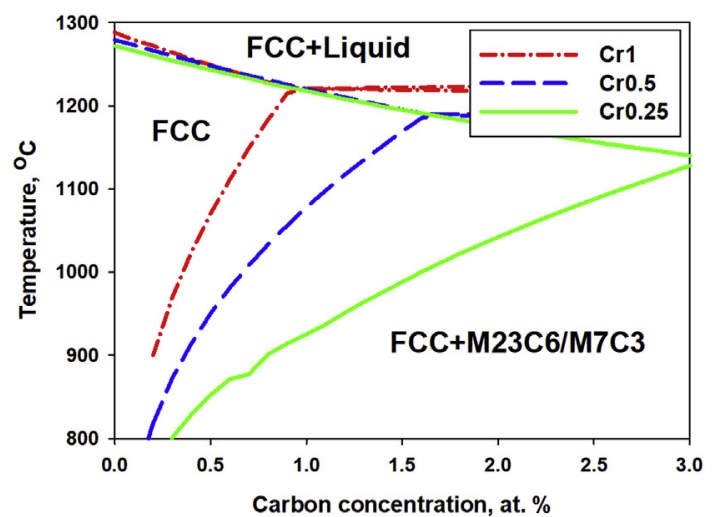

Fig. 8. Boundaries of the single fcc phase field in the carbon-doped $\mathrm{Co}_{1} \mathrm{Cr}_{\mathrm{X}} \mathrm{Fe}_{1} \mathrm{Mn}_{1} \mathrm{Ni}_{1}$ alloys (subscripts indicate the molar concentrations of the respective elements) depending on the $\mathrm{Cr}$ and $\mathrm{C}$ concentrations. The equilibrium phase diagrams were constructed using the Thermo-Calc software.

possible alternative explanations; in broad sense all suggest different kinds of interaction between the defects (dislocations) and the carbon atoms. Further studies are needed to establish the nature of the serrations in the program alloys.

Meanwhile the observed increase in lattice friction stress along with a decrease in SFE [41] both due to the addition of carbon and a decrease in temperature from 293 to $77 \mathrm{~K}$ can result in the intensification of planar slip [64]. That is why the most obvious planar slip was observed at $77 \mathrm{~K}$ in the alloy with 2 at. \% of carbon (Fig. $7 \mathrm{f}$ ) and an increase in the carbon content resulted in tending to planar slip even at room temperature (Fig. 7 a,c,e). Apparently, planar slip increased the strain hardening capacity (Fig. 6) of the alloy. Formation of dislocation pile-ups (Fig. 7c) also increased strain hardening rate at the initial stages of deformation, similarly to the carbon-doped $\mathrm{Fe}_{40.4} \mathrm{Ni}_{11.3} \mathrm{Mn}_{34.8} \mathrm{Al}_{7.5} \mathrm{Cr}_{6}$ HEAs [35]. Yet the ductility of the alloys became lower with increasing the carbon content (Fig. 4, Table 2). Evidentially, this is the consequence of increased strength together with the lack of new effective strengthening mechanisms (e.g. TWIP/TRIP) in the alloys with higher carbon percentage.

To sum up, the present study has revealed that the strength of the single fcc solid solution phase HEAs at $77 \mathrm{~K}$ can be substantially increased by the addition of carbon, without noticeable loss in ductility. This finding may open new pathways for improving impressive fracture toughness, already demonstrated by such alloys $[18,30]$. The carbon-doped alloys with high ductility, strength, and toughness can be considered as promising materials for cryogenic structural applications, for example, for natural gas transportation [67]. However, further studies on the effect of carbon on fcc HEAs toughness and other properties at different temperatures are required to verify these suggestions.

\section{Conclusion}

In the present work structure, mechanical properties and deformation mechanisms of the as-cast $\mathrm{CoCr}_{0.25} \mathrm{FeMnNi}$ alloys doped with $0-2$ at.\% of carbon were examined during uniaxial tension at 293 and $77 \mathrm{~K}$. Following conclusions were drawn:

1) In the as-cast condition the alloys had the single fcc phase coarse-grained structure when carbon content was in the range of $0-1$ at.\%. An insignificant fraction of the $M_{7} C_{3}$ carbides was found in the alloy with 2 at.\% of carbon. Higher solubility of carbon in the $\mathrm{CoCr}_{0.25} \mathrm{FeMnNi}$ alloy in comparison with the equiatomic CoCrFeMnNi one was proven by ThermoCalc calculations to be the result of a reduction in the $\mathrm{Cr}$ concentration.

2) Tensile mechanical properties of the alloys showed a strong dependence on the carbon content and testing temperature. Strength of the alloys increased with an increase in the carbon concentration and with a decrease in the testing temperature. For example, yield strength at room temperature increased from $185 \mathrm{MPa}$ to $320 \mathrm{MPa}$ with an increase in the carbon concentration from 0 to 2 at.\%, while corresponding values at $77 \mathrm{~K}$ were $315 \mathrm{MPa}$ and $605 \mathrm{MPa}$, respectively. The increase in strength was attributed to the carbon-induced solid solution strengthening effect, which was estimated as of $67 \mathrm{MPa} / a t \%$ at $293 \mathrm{~K}$ and $178 \mathrm{MPa} / \mathrm{at} \%$ at $77 \mathrm{~K}$. Increased solid solution strengthening at the lower temperature agreed with an anticipated increase in lattice friction. Ductility of the alloys slightly decreased with an increase in the carbon percentage and generally was higher at $77 \mathrm{~K}$ in comparison to ductility at $293 \mathrm{~K}$.

3) Plastic deformation in the program alloys was associated with dislocations slip both at $293 \mathrm{~K}$ and $77 \mathrm{~K}$. A decrease in temperature and an increase in the carbon concentration increased the inclination to planar slip during deformation.

\section{Acknowledgments}

The authors gratefully acknowledge the financial support from the Russian Science Foundation Grant No. 18-19-00003. The authors are grateful to the personnel of the Joint Research Center, «Technology and Materials», Belgorod State University, for their assistance with the instrumental analysis.

\section{References}

[1] J.W. Yeh, S.K. Chen, S.J. Lin, J.Y. Gan, T.S. Chin, T.T. Shun, C.H. Tsau, S.Y. Chang, Nanostructured high-entropy alloys with multiple principal elements: novel alloy design concepts and outcomes, Adv. Eng. Mater. 6 (2004) 299-303+274, https://doi.org/10.1002/adem.200300567.

[2] D.B. Miracle, O.N. Senkov, A critical review of high entropy alloys and related concepts, Acta Mater. 122 (2017) 448-511, https://doi.org/10.1016/ j.actamat.2016.08.081.

[3] O.N. Senkov, J.D. Miller, D.B. Miracle, C. Woodward, Accelerated exploration of multi-principal element alloys with solid solution phases, Nat. Commun. 6 (2015) 6529, https://doi.org/10.1038/ncomms7529.

[4] F. Otto, Y. Yang, H. Bei, E.P.P. George, Relative effects of enthalpy and entropy on the phase stability of equiatomic high-entropy alloys, Acta Mater. 61 (2013) 2628-2638, https://doi.org/10.1016/j.actamat.2013.01.042.

[5] M. Laurent-Brocq, L. Perrière, R. Pirès, Y. Champion, From high entropy alloys to diluted multi-component alloys: range of existence of a solid-solution, Mater. Des. 103 (2016) 84-89, https://doi.org/10.1016/j.matdes.2016.04.046.

[6] O.N. Senkov, D.B. Miracle, K.J. Chaput, J.-P. Couzinie, Development and exploration of refractory high entropy alloys-a review, J. Mater. Res. 33 (2018) 3092-3128, https://doi.org/10.1557/jmr.2018.153.

[7] Y. Zhang, T.T. Zuo, Z. Tang, M.C. Gao, K.A. Dahmen, P.K. Liaw, Z.P. Lu, Microstructures and properties of high-entropy alloys, Prog. Mater. Sci. 61 (2014), https://doi.org/10.1016/j.pmatsci.2013.10.001.

[8] S. Gorsse, D.B. Miracle, O.N. Senkov, Mapping the world of complex concentrated alloys, Acta Mater. 135 (2017) 177-187, https://doi.org/10.1016/ j.actamat.2017.06.027.

[9] Y. Lu, Y. Dong, S. Guo, L. Jiang, H. Kang, T. Wang, B. Wen, Z. Wang, J. Jie, Z. Cao, $\mathrm{H}$. Ruan, T. Li, A promising new class of high-temperature alloys: eutectic high-entropy alloys, Sci. Rep. 4 (2014), https://doi.org/10.1038/srep06200.

[10] Y. Lu, X. Gao, L. Jiang, Z. Chen, T. Wang, J. Jie, H. Kang, Y. Zhang, S. Guo, H. Ruan, Y. Zhao, Z. Cao, T. Li, Directly cast bulk eutectic and near-eutectic high entropy alloys with balanced strength and ductility in a wide temperature range, Acta Mater. 124 (2017) 143-150, https://doi.org/10.1016/j.actamat.2016.11.016.

[11] B. Cantor, I.T.H. Chang, P. Knight, A.J.B. Vincent, Microstructural development in equiatomic multicomponent alloys, Mater. Sci. Eng. A 375 (2004) 213-218, https://doi.org/10.1016/j.msea.2003.10.257.

[12] E.J. Pickering, R. Muñoz-Moreno, H.J. Stone, N.G. Jones, Precipitation in the equiatomic high-entropy alloy CrMnFeCoNi, Scr. Mater. 113 (2016), https:// doi.org/10.1016/j.scriptamat.2015.10.025.

[13] B. Schuh, F. Mendez-Martin, B. Völker, E.P. George, H. Clemens, R. Pippan, A. Hohenwarter, Mechanical properties, microstructure and thermal stability of a nanocrystalline $\mathrm{CoCrFeMnNi}$ high-entropy alloy after severe plastic deformation, Acta Mater. 96 (2015) 258-268, https://doi.org/10.1016/ j.actamat.2015.06.025. 
[14] F. Otto, A. Dlouhý, K.G. Pradeep, M. Kuběnová, D. Raabe, G. Eggeler, E.P. George, Decomposition of the single-phase high-entropy alloy CrMnFeCoNi after prolonged anneals at intermediate temperatures, Acta Mater. 112 (2016), https://doi.org/10.1016/j.actamat.2016.04.005.

[15] M.V. Klimova, D.G. Shaysultanov, S.V. Zherebtsov, N.D. Stepanov, Effect of second phase particles on mechanical properties and grain growth in a CoCrFeMnNi high entropy alloy, Mater. Sci. Eng. A 748 (2019) 228-235, https://doi.org/10.1016/J.MSEA.2019.01.112.

[16] F. Otto, A. Dlouhý, C. Somsen, H. Bei, G. Eggeler, E.P. George, The influences of temperature and microstructure on the tensile properties of a $\mathrm{CoCrFeMnN}$ high-entropy alloy, Acta Mater. 61 (2013) 5743-5755, https://doi.org/ 10.1016/j.actamat.2013.06.018.

[17] A. Gali, E.P. George, Tensile properties of high- and medium-entropy alloys, Intermetallics 39 (2013) 74-78, https://doi.org/10.1016/j.intermet.2013. 03.018 .

[18] B. Gludovatz, A. Hohenwarter, D. Catoor, E.H. Chang, E.P. George, R.O. Ritchie, A fracture-resistant high-entropy alloy for cryogenic applications, Science (80-. ) 345 (2014) 1153-1158, https://doi.org/10.1126/science.1254581.

[19] Z. Zhang, M.M. Mao, J. Wang, B. Gludovatz, Z. Zhang, S.X. Mao, E.P. George, Q. Yu, R.O. Ritchie, Nanoscale origins of the damage tolerance of the highentropy alloy CrMnFeCoNi, Nat. Commun. 6 (2015) 10143, https://doi.org/ 10.1038/ncomms10143.

[20] C. Haase, L.A. Barrales-Mora, Influence of deformation and annealing twinning on the microstructure and texture evolution of face-centered cubic highentropy alloys, Acta Mater. 150 (2018) 88-103, https://doi.org/10.1016/ j.actamat.2018.02.048.

[21] C. Haase, L.A. Barrales-Mora, C. Haase, L.A. Barrales-Mora, From highmanganese steels to advanced high-entropy alloys, Met 9 (2019) 726, https://doi.org/10.3390/MET9070726, 9 (2019) 726.

[22] N. Stepanov, M. Tikhonovsky, N. Yurchenko, D. Zyabkin, M. Klimova S. Zherebtsov, A. Efimov, G. Salishchev, Effect of cryo-deformation on structure and properties of CoCrFeNiMn high-entropy alloy, Intermetallics 59 (2015) 8-17, https://doi.org/10.1016/j.intermet.2014.12.004.

[23] N.D. Stepanov, D.G. Shaysultanov, R.S. Chernichenko, D.M. Ikornikov, V.N. Sanin, S.V. Zherebtsov, Mechanical properties of a new high entropy alloy with a duplex ultra-fine grained structure, Mater. Sci. Eng. A 728 (2018) 54-62, https://doi.org/10.1016/j.msea.2018.04.118.

[24] S.J. Sun, Y.Z. Tian, H.R. Lin, X.G. Dong, Y.H. Wang, Z.J. Zhang, Z.F. Zhang, Enhanced strength and ductility of bulk CoCrFeMnNi high entropy alloy having fully recrystallized ultrafine-grained structure, Mater. Des. 133 (2017) 122-127, https://doi.org/10.1016/j.matdes.2017.07.054.

[25] Y.H. Wang, Z.F. Zhang, S.J. Sun, H.J. Yang, Y.Z. Tian, H.R. Lin, X.G. Dong, Transition of twinning behavior in CoCrFeMnNi high entropy alloy with grain refinement, Mater. Sci. Eng. A 712 (2017) 603-607, https://doi.org/10.1016 j.msea.2017.12.022.

[26] S. Zherebtsov, N. Stepanov, Y. Ivanisenko, D. Shaysultanov, N. Yurchenko M. Klimova, G. Salishchev, Evolution of microstructure and mechanical properties of a CoCrFeMnNi high-entropy alloy during high-pressure torsion at room and cryogenic temperatures, Metals (Basel) 8 (2018), https://doi.org/ 10.3390/met8020123.

[27] B. Schuh, R. Pippan, A. Hohenwarter, Tailoring bimodal grain size structures in nanocrystalline compositionally complex alloys to improve ductility, Mater. Sci. Eng. A 748 (2019) 379-385, https://doi.org/10.1016/j.msea.2019.01.073.

[28] H. Shahmir, J. He, Z. Lu, M. Kawasaki, T.G. Langdon, Effect of annealing on mechanical properties of a nanocrystalline CoCrFeNiMn high-entropy alloy processed by high-pressure torsion, Mater. Sci. Eng. A 676 (2016) 294-303, https://doi.org/10.1016/j.msea.2016.08.118.

[29] I.L. Velo, F.J. Gotor, M.D. Alcalá, C. Real, J.M. Córdoba, Fabrication and characterization of WC-HEA cemented carbide based on the CoCrFeNiMn high entropy alloy, J. Alloy. Comp. (2018), https://doi.org/10.1016/j.jallcom.2018. 02.292 .

[30] B. Gludovatz, A. Hohenwarter, K.V.S. Thurston, H. Bei, Z. Wu, E.P. George, R.O. Ritchie, Exceptional damage-tolerance of a medium-entropy alloy $\mathrm{CrCoNi}$ at cryogenic temperatures, Nat. Commun. (2016), https://doi.org/10.1038 ncomms10602.

[31] Z. Zhang, H. Sheng, Z. Wang, B. Gludovatz, Z. Zhang, E.P. George, Q. Yu, S.X. Mao, R.O. Ritchie, Dislocation mechanisms and 3D twin architectures generate exceptional strength-ductility-toughness combination in $\mathrm{CrCoN}$ medium-entropy alloy, Nat. Commun. 8 (2017) 14390, https://doi.org/ 10.1038/ncomms14390.

[32] Y.H. Jo, W.-M. Choi, S.S. Sohn, H.S. Kim, B.-J. Lee, S. Lee, Role of brittle sigma phase in cryogenic-temperature-strength improvement of non-equi-atomic Fe-rich VCrMnFeCoNi high entropy alloys, Mater. Sci. Eng. A 724 (2018) 403-410, https://doi.org/10.1016/J.MSEA.2018.03.115.

[33] Y.H. Jo, S. Jung, W.M. Choi, S.S. Sohn, H.S. Kim, B.J. Lee, N.J. Kim, S. Lee, Cryogenic strength improvement by utilizing room-temperature deformation twinning in a partially recrystallized VCrMnFeCoNi high-entropy alloy, Nat. Commun. 8 (2017) 15719, https://doi.org/10.1038/ncomms15719.

[34] Z. Wang, I. Baker, Interstitial strengthening of a f.c.c. FeNiMnAlCr high entropy alloy, Mater. Lett. 180 (2016) 153-156, https://doi.org/10.1016/j.matlet. 2016.05.122.

[35] Z. Wang, I. Baker, W. Guo, J.D. Poplawsky, The effect of carbon on the microstructures, mechanical properties, and deformation mechanisms of thermo-mechanically treated Fe40.4Ni11.3Mn34.8Al7.5Cr6 high entropy alloys, Acta Mater. 126 (2017) 346-360, https://doi.org/10.1016 j.actamat.2016.12.074

[36] Z. Li, Interstitial equiatomic CoCrFeMnNi high-entropy alloys: carbon content, microstructure, and compositional homogeneity effects on deformation behavior, Acta Mater. 164 (2019) 400-412, https://doi.org/10.1016/ j.actamat.2018.10.050.

[37] J. Chen, Z. Yao, X. Wang, Y. Lu, X. Wang, Y. Liu, X. Fan, Effect of C content on microstructure and tensile properties of as-cast CoCrFeMnNi high entropy alloy, Mater. Chem. Phys. 210 (2018) 136-145, https://doi.org/10.1016/ j.matchemphys.2017.08.011.

[38] L.B. Chen, R. Wei, K. Tang, J. Zhang, F. Jiang, L. He, J. Sun, Heavy carbon alloyed FCC-structured high entropy alloy with excellent combination of strength and ductility, Mater. Sci. Eng. A 716 (2018) 150-156, https://doi.org/10.1016/ j.msea.2018.01.045.

[39] J.Y. Ko, S.I. Hong, Microstructural evolution and mechanical performance of carbon-containing CoCrFeMnNi-C high entropy alloys, J. Alloy. Comp. 743 (2018) 115-125, https://doi.org/10.1016/j.jallcom.2018.01.348.

[40] T. Huang, L. Jiang, C. Zhang, H. Jiang, Y. Lu, T. Li, Effect of carbon addition on the microstructure and mechanical properties of CoCrFeNi high entropy alloy, Sci. China Technol. Sci. 61 (2018) 117-123, https://doi.org/10.1007/s11431017-9134-6.

[41] Z. Wang, I. Baker, Z. Cai, S. Chen, J.D. Poplawsky, W. Guo, The effect of interstitial carbon on the mechanical properties and dislocation substructure evolution in Fe40.4Ni11.3Mn34.8Al7.5Cr6 high entropy alloys, Acta Mater. 120 (2016), https://doi.org/10.1016/j.actamat.2016.08.072.

[42] N.D. Stepanov, N.Y. Yurchenko, M.A. Tikhonovsky, G.A. Salishchev, Effect of carbon content and annealing on structure and hardness of the CoCrFeNiMnbased high entropy alloys, J. Alloy. Comp. 687 (2016) 59-71, https://doi.org/ 10.1016/j.jallcom.2016.06.103.

[43] N.D. Stepanov, D.G. Shaysultanov, R.S. Chernichenko, N.Y. Yurchenko, S.V. Zherebtsov, M.A. Tikhonovsky, G.A. Salishchev, Effect of thermomechanical processing on microstructure and mechanical properties of the carboncontaining CoCrFeNiMn high entropy alloy, J. Alloy. Comp. 693 (2017) 394-405, https://doi.org/10.1016/j.jallcom.2016.09.208.

[44] M. Klimova, N. Stepanov, D. Shaysultanov, R. Chernichenko, N. Yurchenko, V. Sanin, S. Zherebtsov, Microstructure and mechanical properties evolution of the $\mathrm{Al}$, C-containing CoCrFeNiMn-type high-entropy alloy during cold rolling, Materials (Basel) 11 (2017) 53, https://doi.org/10.3390/ma11010053.

[45] M.V. Klimova, D.G. Shaysultanov, R.S. Chernichenko, V.N. Sanin, N.D. Stepanov, S.V.Zherebtsov, A.N. Belyakov, Recrystallized microstructures and mechanical properties of a C-containing CoCrFeNiMn-type high-entropy alloy, Mater. Sci. Eng. A 740-741 (2019) 201-210, https://doi.org/10.1016/j.msea.2018.09.113.

[46] Z. Wu, C.M. Parish, H. Bei, Nano-twin mediated plasticity in carbon-containing FeNiCoCrMn high entropy alloys, J. Alloy. Comp. 647 (2015) 815-822, https:// doi.org/10.1016/j.jallcom.2015.05.224.

[47] Z. Li, C.C. Tasan, H. Springer, B. Gault, D. Raabe, Interstitial atoms enable joint twinning and transformation induced plasticity in strong and ductile highentropy alloys, Sci. Rep. 7 (2017) 40704, https://doi.org/10.1038/srep40704.

[48] M. Wang, Z. Li, D. Raabe, In-situ SEM observation of phase transformation and twinning mechanisms in an interstitial high-entropy alloy, Acta Mater. 147 (2018) 236-246, https://doi.org/10.1016/j.actamat.2018.01.036.

[49] D. Shaysultanov, N. Stepanov, S. Malopheyev, I. Vysotskiy, V. Sanin, S. Mironov, R. Kaibyshev, G. Salishchev, S. Zherebtsov, Friction stir welding of a carbon-doped CoCrFeNiMn high-entropy alloy, Mater. Char. 145 (2018) 353-361, https://doi.org/10.1016/J.MATCHAR.2018.08.063.

[50] H. Cheng, H.Y. Wang, Y.C. Xie, Q.H. Tang, P.O. Dai, Controllable fabrication of a carbide-containing FeCoCrNiMn high-entropy alloy: microstructure and mechanical properties, Mater. Sci. Technol. 33 (2017) 2032-2039, https:// doi.org/10.1080/02670836.2017.1342367.

[51] A. Saeed-Akbari, J. Imlau, U. Prahl, W. Bleck, Derivation and variation in composition-dependent stacking fault energy maps based on subregular solution model in high-manganese steels, Metall. Mater. Trans. A Phys. Metall. Mater. Sci. 40 (2009) 3076-3090, https://doi.org/10.1007/s11661-009-0050-

[52] G. Laplanche, A. Kostka, C. Reinhart, J. Hunfeld, G. Eggeler, E.P. George, Reasons for the superior mechanical properties of medium-entropy $\mathrm{CrCoNi}$ compared to high-entropy CrMnFeCoNi, Acta Mater. (2017), https://doi.org/10.1016/ j.actamat.2017.02.036.

[53] Z. Wang, H. Bei, I. Baker, Microband induced plasticity and the temperature dependence of the mechanical properties of a carbon-doped FeNiMnAlCr high entropy alloy, Mater. Char. 139 (2018) 373-381, https://doi.org/10.1016/ J.MATCHAR.2018.03.017.

[54] G.A. Salishchev, M.A. Tikhonovsky, D.G. Shaysultanov, N.D. Stepanov, A.V. Kuznetsov, I.V. Kolodiy, A.S. Tortika, O.N. Senkov, Effect of Mn and v on structure and mechanical properties of high-entropy alloys based on CoCrFeNi system, J. Alloy. Comp. 591 (2014) 11-21, https://doi.org/10.1016/j.jallcom. 2013.12.210.

[55] V.G. (Valentin G. Gavriliuk, H. Berns, High Nitrogen Steels : Structure, Properties, Manufacture, Applications, Springer Berlin Heidelberg, 1999.

[56] O. Bouaziz, H. Zurob, B. Chehab, J.D. Embury, S. Allain, M. Huang, Effect of chemical composition on work hardening of Fe-Mn-C TWIP steels, Mater. Sci. Technol. 27 (2011) 707-709, https://doi.org/10.1179/026708309X12535 382371852.

[57] Z. Wu, H. Bei, G.M. Pharr, E.P. George, Temperature dependence of the mechanical properties of equiatomic solid solution alloys with face-centered cubic crystal structures, Acta Mater. 81 (2014), https://doi.org/10.1016/ 
j.actamat.2014.08.026.

[58] O. Grässel, L. Krüger, G. Frommeyer, L. Meyer, High strength $\mathrm{Fe}-\mathrm{Mn}-(\mathrm{Al}, \mathrm{Si})$ TRIP/TWIP steels development - properties - application, Int. J. Plast. 16 (2000) 1391-1409, https://doi.org/10.1016/S0749-6419(00)00015-2.

[59] J.D. Yoo, K.-T. Park, Microband-induced plasticity in a high $\mathrm{Mn}-\mathrm{Al}-\mathrm{C}$ light steel, Mater. Sci. Eng. A 496 (2008) 417-424, https://doi.org/10.1016/ j.msea.2008.05.042.

[60] G. Laplanche, A. Kostka, O.M.M. Horst, G. Eggeler, E.P.P. George, Microstructure evolution and critical stress for twinning in the CrMnFeCoNi highentropy alloy, Acta Mater. 118 (2016) 152-163, https://doi.org/10.1016/ j.actamat.2016.07.038

[61] A.J. Zaddach, R.O. Scattergood, C.C. Koch, Tensile properties of low-stacking fault energy high-entropy alloys, Mater. Sci. Eng. A 636 (2015) 373-378, https://doi.org/10.1016/j.msea.2015.03.109.

[62] W.-M. Choi, Y.H. Jo, S.S. Sohn, S. Lee, B.-J. Lee, Understanding the physical metallurgy of the $\mathrm{CoCrFeMnNi} \mathrm{high-entropy} \mathrm{alloy:} \mathrm{an} \mathrm{atomistic} \mathrm{simulation}$ study, Npj Comput. Mater. 4 (2018) 1, https://doi.org/10.1038/s41524-0170060-9.
[63] V. Gerold, H.P. Karnthaler, On the origin of planar slip in f.c.c. alloys, Acta Metall. 37 (1989) 2177-2183, https://doi.org/10.1016/0001-6160(89)90143-

[64] S.I. Hong, C. Laird, Mechanisms of slip mode modification in F.C.C. solid solutions, Acta Metall. Mater. 38 (1990) 1581-1594, https://doi.org/10.1016 0956-7151(90)90126-2.

[65] W. Song, J. Houston, W. Song, J.E. Houston, Local deformation and Mn-C shortrange ordering in a high-Mn Fe-18Mn-0.6C steel, Metals (Basel) 8 (2018) 292, https://doi.org/10.3390/met8050292.

[66] B.C. De Cooman, Y. Estrin, S.K. Kim, Twinning-induced plasticity (TWIP) steels, Acta Mater. 142 (2018) 283-362, https://doi.org/10.1016/j.actamat.2017. 06.046.

[67] M.J. Jang, H. Kwak, Y.W. Lee, Y. Jeong, J. Choi, Y.H. Jo, W.-M. Choi, H.J. Sung, E.Y. Yoon, S. Praveen, S. Lee, B.-J. Lee, M.I. Abd El Aal, H.S. Kim, Plastic deformation behavior of $40 \mathrm{Fe}-25 \mathrm{Ni}-15 \mathrm{Cr}-10 \mathrm{Co}-10 \mathrm{~V}$ high-entropy alloy for cryogenic applications, Met. Mater. Int. 25 (2019) 277-284, https://doi.org/ 10.1007/s12540-018-0184-6. 